\title{
PRODUCTION OF MEDIUM CHAIN LENGTH POLYHYDROXYALKANOATES FROM Cupriavidus necator WITH BEESWAX HYDROLYZATES AS CARBON SOURCE
}

\author{
Samuel QUINTANAR-GÓMEZ ${ }^{1}$, Arturo ABREU-CORONA², Evelyn ZAMUDIO-PÉREZ ${ }^{3}$, \\ Genaro VARGAS-HERNÁNDEZ ${ }^{1}$, Alejandro TÉLLEZ-JURADO ${ }^{1}$ and Jorge GRACIDA-RODRÍGUEZ ${ }^{*}$
}

${ }^{1}$ Universidad Politécnica de Pachuca, km 20 carretera Pachuca-Ciudad Sahagún, Ex-Hacienda de Santa Bárbara, 43830 Zempoala, Hidalgo, México

${ }^{2}$ Departamento de Ciencias Naturales, Universidad Autonóma Metropolitana, Unidad Cuajimalpa, Av. Vasco de Quiroga 4871, Col. Santa Fe Cuajimalpa, 05300 Ciudad de México, México

${ }^{3}$ Centro de Investigación y Desarrollo Tecnológico en Electroquímica, Parque Sanfandila s/n, 76703 Pedro Escobedo, Querétaro, México

${ }^{4}$ Biotecnología, Facultad de Química, Universidad Autónoma de Querétaro, Cerro de las Campanas s/n, Las Campanas, 76010 Santiago de Querétaro, Querétaro, México

*Author for correspondence: gracidaj@netscape.net

(Received May 2017; accepted November 2017)

Key words: biopolymers, DSC, mcl-PHA, NMR, fed-batch fermentation

\begin{abstract}
This study demonstrates that using beeswax hydrolyzates (Hw), short- or mediumchain-length polyhydroxyalkanoates (scl-mcl-PHA) can be obtained by a three stages fed-batch fermentation system. The fed batch fermentations were conducted with a strain of Cupriavidus necator. Glucose and ammonium sulphate as carbon and nitrogen sources, respectively, were used in a first and second culture stages. In the third stage (production of scl-mcl-PHA) a fresh medium was fed with $\mathrm{Hw}$ as a carbon source at a concentration of $5 \mathrm{~g} / \mathrm{L}$, obtaining $8.91 \mathrm{~g} / \mathrm{L}$ of intracellular scl-mcl-PHA and $13.64 \mathrm{~g} / \mathrm{L}$ of biomass, which resulted in $65.3 \% \mathrm{w} / \mathrm{w}$ of scl-mcl-PHA. Using nuclear magnetic resonance, the presence of scl and mcl monomers, 3-hydroxybutyrate $(3 \mathrm{HB})$ and 3 -hydroxydecanoate (3HD) was determined. The percentage of comonomer incorporation different to $3 \mathrm{HB}$ was $4.6 \mathrm{~mol} \%$. A glass transition temperature $\left(\mathrm{T}_{\mathrm{g}}\right)$ of $-50{ }^{\circ} \mathrm{C}$ and a melting temperature $\left(\mathrm{T}_{\mathrm{m}}\right)$ of $79.8{ }^{\circ} \mathrm{C}$ were determined for the scl-mcl-PHA (3HB-co-3HDD).
\end{abstract}

Palabras clave: biopolímeros, DSC, mcl-PHA, RMN, fermentación lote alimentado

\section{RESUMEN}

Este estudio demuestra que mediante el uso de hidrolizados de cera de abejas (Hw) pueden obtenerse polihidroxialcanoatos de cadena corta o media (scl-mcl-PHA), mediante un sistema de fermentación por lote alimentado de tres etapas. Las fermentaciones por lote alimentado se llevaron a cabo con una cepa de Cupriavidus necator. Se usaron glucosa y sulfato de amonio como fuentes de carbono y nitrógeno, respectivamente, en una primera y segunda etapas de cultivo. En la tercera etapa (producción de scl-mclPHA) se alimentó medio fresco con Hw como fuente de carbono a una concentración 
de $5 \mathrm{~g} / \mathrm{L}$, obteniéndose $8.91 \mathrm{~g} / \mathrm{L}$ de scl-mcl-PHA intracelular y $13.64 \mathrm{~g} / \mathrm{L}$ de biomasa, con $65.3 \% \mathrm{p} / \mathrm{p}$ de scl-mcl-PHA. Utilizando resonancia magnética nuclear se determinó la presencia de monómeros de scl y mcl, 3-hidroxibutirato (3HB) y 3-hidroxidecanoato (3HD). El porcentaje de incorporación de comonómeros diferente a 3HB fue de $4.6 \%$ moles. Se determinó una temperatura de transición vitrea $(\mathrm{Tg})$ de $-50{ }^{\circ} \mathrm{C}$ y una temperatura de fusión (Tm) de $79.8^{\circ} \mathrm{C}$ para el scl-mcl-PHA (3HB-co-3HDD).

\section{INTRODUCTION}

Polyhydroxyalkanoates (PHA) are natural, renewable and biocompatible biopolymers, produced intracellularly in bacteria, with great importance due to environmental issues regarding accumulation of non biodegradable plastic waste. PHA are stereospecific isotactic polymers synthesized by many microorganisms. They are classified according to the length of the side chain of their monomers: short chain (scl-PHA), with three to five carbon atoms and medium chain length (mcl-PHA), six to 14 carbon atoms (Liu et al. 2011). The composition and amount of intracellular PHA are related to the carbon source, the $\mathrm{C} / \mathrm{N}$ ratio, microorganisms used and the synthesis process (Jiang 2010).

Several studies have evaluated various renewable carbon sources, such as canola oil (Rathinasabapathy et al. 2013) and used cooking oil, which have demonstrated great biotechnological potential for the production of mcl-PHA (Cruz et al. 2015). During the biosynthesis of PHA by Cupriavidus necator (formerly Wautersia eutropha $>$ Ralstonia eutropha $>$ Alcaligenes eutrophus) from fatty acids, López-Cuéllar et al. (2011), Rathinasabapathy et al. (2013) and Inomata et al. (2014) demonstrated that $C$. necator was able to synthesize mcl-PHA using fructose and canola oil as substrates in a three stages fed-batch system, although it has been reported that the PHA synthase of C. necator is strictly specific for scl-PHA monomers (Slater et al. 1992).

The synthesized mcl-PHA presented three medium chain length comonomers, 3-hydroxyvalerate $(3 \mathrm{HV}), 3$-hydroxyoctanoate $(3 \mathrm{HO})$, and 3 -hydroxydecanoate (3HD) bound to $3 \mathrm{HB}$. This copolymer showed improvement in its thermal and mechanical properties (melting temperature $\left[\mathrm{T}_{\mathrm{m}}\right]$ $\left.=176{ }^{\circ} \mathrm{C}\right)$ compared to pure PHB $\left(\mathrm{T}_{\mathrm{m}}=179{ }^{\circ} \mathrm{C}\right)$. Loo and Sudesh (2007) synthesized the copolymer poly(3-hydroxybutyrate-co-3-hydroxyhexanoate) $[\mathrm{P}(3 \mathrm{HB}-\mathrm{co}-3 \mathrm{HHx})]$ with incorporation of $5 \mathrm{~mol} \%$ of 3-hydroxyhexanoate $(3 \mathrm{HHx})$ units that reduce the melting point from $180{ }^{\circ} \mathrm{C}$ to less than $155^{\circ} \mathrm{C}$. Due to this characteristic, PHA have attracted much attention as a biodegradable alternative to traditional petrochemical plastics and can replace these materials in many applications.

Budde et al. (2011) described a method for the development of $R$. eutropha cultured in vegetable oil using emulsifying agents. They reported that Triton $\mathrm{X}-100$ at concentrations of $0.05 \%(\mathrm{v} / \mathrm{v})$ in presence of vegetable oil can emulsify $1 \%(\mathrm{v} / \mathrm{v})$ palm oil crop, rendering it into an available carbon source. Like vegetable oils, beeswax is a renewable carbon source that has a great demand on the world market. Beeswax has a wide range of uses in cosmetics manufacturing, candle processing, agriculture, and pharmaceutical and food industries (Zhang and Xiao 2013). These manufacturing processes require first-class beeswax that has not been overheated. Unpurified raw wax and its waste may be potential substrates for mcl-PHA synthesis. In terms of cost of substrates for fermentation, the average price of unpurified organic beeswax is 3 to $8 \mathrm{USD} / \mathrm{kg}$ (Bradbear 2004), which is comparable to the 6.5 to 7.8 $\mathrm{USD} / \mathrm{kg}$ cost of sodium octanoate/sodium caprylate (Alibaba 2017).

Beeswax is a mixture of wax acid esters, and it has not been reported as a carbon source for PHA synthesis. When beeswax is methanolyzed with alkali, it generates hydrolysates rich in fractions of fatty alcohols and acids (Maia and Nunes 2013). Some studies suggest that fatty alcohols can be converted to fatty acids providing precursors for synthesis of mcl-PHA by $\beta$-oxidation (Jiang 2010). This study evaluated the effect of $\mathrm{Hw}$ as an additional carbon source in the culture medium, on the chemical and thermal properties of scl-mcl-PHA obtained during the accumulation phase of $C$. necator in a three-stages fed-batch system.

\section{MATERIALS AND METHODS}

\section{Microorganism and medium}

C. necator ATCC 17699 was propagated in Luria Bertani broth (LB) and incubated at $30{ }^{\circ} \mathrm{C}$. The inoculum for all assays was prepared by transferring 
$100 \mathrm{~mL}$ of seed flask cultivation with LB medium, incubated for $36 \mathrm{~h}$ at $150 \mathrm{rpm}$ and $30^{\circ} \mathrm{C}$ on a rotary shaker (Excella E24, New Brunswick Scientific). The fermentation medium of stage 1 (batch culture), first fed-batch culture in stage 2 (biomass production), and second fed-batch culture in stage 3 are described in table I (synthesis of mcl-PHA fractions). The trace element solution was defined by Shang et al. (2004).

\section{Fermentation}

The cultures were done in triplicate, in a $5 \mathrm{~L}$ fermentation unit (FA-5000, VICHI). The content of the seed flask $(10 \% \mathrm{v} / \mathrm{v})$ was transferred to a fermentation medium under the same conditions described above, $\mathrm{pH} 7.0$ controlled with $2 \mathrm{M} \mathrm{NaOH}$ and $0.47 \mathrm{M} \mathrm{HCl}$. Samples were taken every $3 \mathrm{~h}$ to quantify glucose, ammonium sulphate, biomass and PHA. The fermentation was done in a modified three stages method (López-Cuéllar et al. 2011):

- Stage 1: Initial batch cultivation with $\mathrm{C} / \mathrm{N}=14$, and $3.9 \mathrm{~L}$ volume.

- Stage 2: Biomass production by a fed batch system. A glucose solution of $30 \mathrm{~g} / \mathrm{L}$ was fed at $50 \mathrm{~mL} / \mathrm{h}$ (MasterFlex L/S Model 77200-62) (Chakraborty et al. 2012) to achieve a high density culture.

- Stage 3: Synthesis of scl-mcl-PHA under nitrogen limitation in the culture medium, using Hw as a co-substrate (together with remaining glucose from the previous stages) at a concentration of $5 \mathrm{~g} / \mathrm{L}$, in presence of $0.43 \mathrm{~g} / \mathrm{L}$ Triton X-100 (Sigma-Aldrich), three times its CMC (Budde et al. 2011) added at $0.33 \mathrm{~L} / \mathrm{h}$.

\section{Analytical techniques}

Dry weight $(\mathrm{X})$ was determined by gravimetry, defining residual biomass (rX) as the concentration of $X$ without PHA (Budde et al. 2011). Glucose concentration was determined by the DNS method (Barbosa et al. 2005). Quantification of ammonium sulphate was carried out with the Weatherburn method (López-Cuéllar et al. 2011). The amount of residual beeswax hydrolysates ( $\mathrm{rHw}$ ) was defined as the concentration of recovered $\mathrm{Hw}$, subtracting the centrifuged sample concentration determined by the modified equation described by Budde et al. (2011):

$\begin{aligned} & \text { residual } \\ & \text { hydrolized wax }\end{aligned}=\begin{aligned} & \text { recovered } \\ & \text { mass }\end{aligned}\left(\frac{V_{\text {org }}}{V_{\text {transferred }}}\right)\left(\frac{1}{V_{\text {sample }}}\right)$

where $V_{\text {org }}$ is the volume of the organic phase after the extraction. Because the solvent mixture includes methanol, not all the solvent remains in the organic phase after contact with the aqueous medium. We measured $V_{\text {org }}$ to be $15 \mathrm{~mL}$ when using chloroform/ methanol 10:5. $V_{\text {transferred was }} 5 \mathrm{~mL}$ and $V_{\text {sample }}$ (volume of medium taken from the culture) was $10 \mathrm{~mL}$.

\section{PHA purification}

PHA was purified using chloroform extraction during 10 min with reflux and then it was precipitated with cold hexane after filtering cellular residues (Nurbas and Kutsal 2004). This procedure was repeated three times to carry out the purification of the polymer and avoid the presence of debris cells and possible residual metabolites present in beeswax. The exceeding solvent was removed by evaporation (R-210, BUCHI).

\section{PHA characterization}

Nuclear magnetic resonance (NMR) was carried out to elucidate the structure of PHA (Avance PDX-300, Bruker). Deuterated chloroform $\left(\mathrm{CDCl}_{3}\right)$ was used as solvent. The spectra corresponding to ${ }^{1} \mathrm{H}$ and ${ }^{13} \mathrm{C}$ were analyzed with specialized software (MestReNova V. 6.0). Experiments were performed

TABLE I. COMPOSITION OF THE CULTURE MEDIUM

\begin{tabular}{lccc}
\hline Reagents & $\begin{array}{c}\text { Batch culture } \\
(\mathrm{g} / \mathrm{L})\end{array}$ & $\begin{array}{c}\text { First fed-batch } \\
\text { (biomass production) }(\mathrm{g} / \mathrm{L})\end{array}$ & $\begin{array}{c}\text { Second fed-batch } \\
\text { (synthesis of mcl-PHA fractions) }(\mathrm{g} / \mathrm{L})\end{array}$ \\
\hline Glucose & 20 & 30 & 0 \\
$\left(\mathrm{NH}_{4}\right) \mathrm{SO}_{4}$ & 4.0 & 0.35 & 0 \\
$\mathrm{MgSO}_{4}\left(7 \mathrm{H}_{2} \mathrm{O}\right)$ & 1.2 & 1.20 & 1.2 \\
$\mathrm{KH}_{2} \mathrm{PO}_{4}$ & 4.5 & 4.50 & 4.5 \\
Citric acid & 1.7 & 1.70 & 1.7 \\
Trace element solution $(\mathrm{mL} / \mathrm{L})$ & 10 & 10 & 10 \\
Hydrolized wax & 0 & 0 & 5 \\
\hline
\end{tabular}

mcl-PHA: medium chain length polyhydroxyalkanoates 
using a differential scanning calorimeter (DSC) (Mettler-Toledo DSC822e). The samples (8 mg) were encapsulated in aluminum pans and heated in temperature range from -80 to $220^{\circ} \mathrm{C}$ using a heating rate of $10{ }^{\circ} \mathrm{C} / \mathrm{min}$, taking the second run as valid to determine glass temperatures $\left(\mathrm{T}_{\mathrm{g}}\right)$ and melting temperatures $\left(\mathrm{T}_{\mathrm{m}}\right)$ (Nurbas et al. 2004).

\section{RESULTS AND DISCUSSION}

\section{scl-mcl-PHA synthesis}

The profile of biomass and PHA production in fedbatch fermentation are shown in figure 1. C. necator produced $13.64 \mathrm{~g} / \mathrm{L}$ of total biomass at the end of the fermentation, when 0.43 and $5 \mathrm{~g} / \mathrm{L}$ of Triton X-100 and $\mathrm{Hw}$ respectively were aggregated and ammonium sulphate was exhausted (Fig. 2c).

The lag phase lasted $12 \mathrm{~h}$, similar to Volova et al. (2014), and the maximum specific growth rate $(\mu)$ in the fed batch stage was $0.20 / \mathrm{h}$, as reported by Chakraborty et al. (2012). The initial ammonium sulphate and glucose concentrations were 3.3 and $20.39 \mathrm{~g} / \mathrm{L}$, respectively (Fig. 2a), with a consumption rate of 0.52 and $0.7 \mathrm{~g} / \mathrm{L} / \mathrm{h}$, respectively, for $21 \mathrm{~h}$ (first stage of fermentation). After $21 \mathrm{~h}$ of culture, $0.3 \mathrm{~g} / \mathrm{L}$ of ammonium sulphate concentration was simultaneously fed with the waxy carbon source (Fig. 2b),

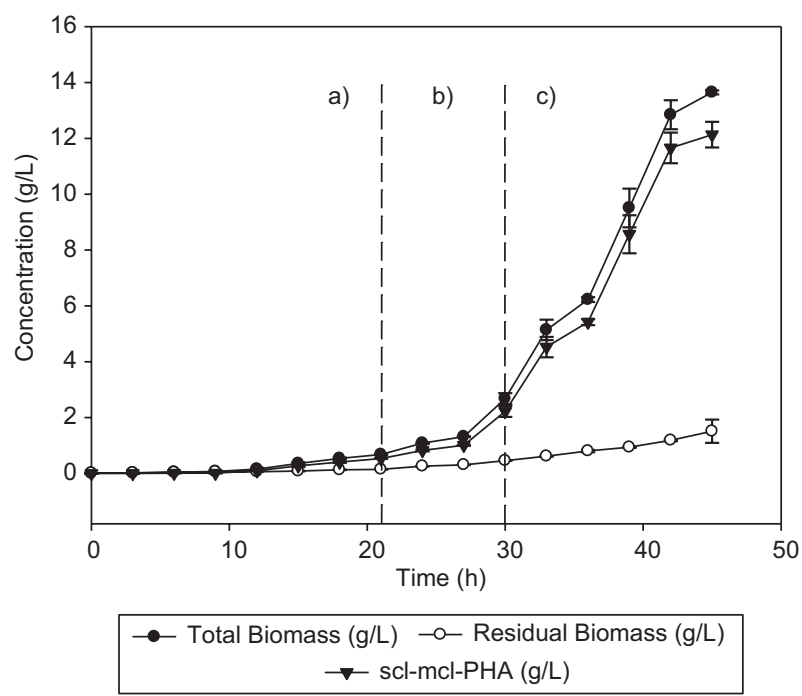

Fig. 1. Profiles of total biomass, residual biomass, and polyhydroxyalkanoate, observed in (a) batch culture, (b) first fed-batch (biomass production), and (c) second fed-batch (synthesis of medium-chain-length polyhydroxyalkanoates (mcl-PHA) fractions, during fermentation of $C$. necator with glucose and beeswax as carbon sources. Lines represent the standard deviation

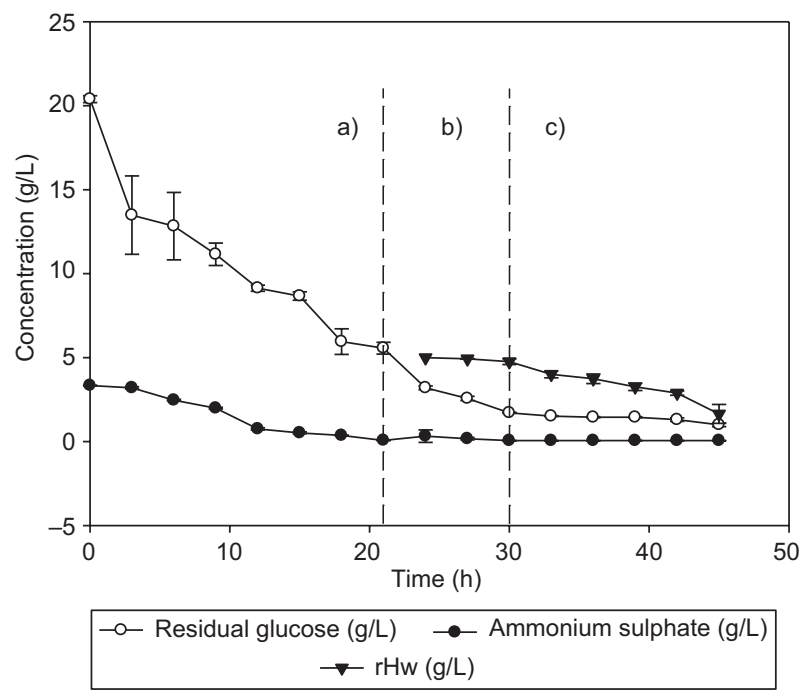

Fig. 2. Profiles of residual ammonium sulphate concentration, residual glucose, and hydrolyzates (Hw) consumption (residual hydrolyzates [rHw inside the fermentor]), observed in (a) batch culture, (b) first fed-batch (biomass production), and (c) second fed-batch (synthesis of medium-chain-length polyhydroxyalkanoates [mclPHA]) fractions, during fermentation of $C$. necator with glucose and $\mathrm{Hw}$ as carbon sources. Lines represent the standard deviation

having a consumption rate of $0.13 \mathrm{~g} / \mathrm{L} / \mathrm{h}$ in order to maintain the metabolism of $C$. necator and stress conditions necessary for intracellular accumulation of PHA (Loo and Sudesh 2007).

At this stage, the feeding of fresh culture medium with $\mathrm{Hw}(\mathrm{C} / \mathrm{N}=200)$ as co-substrate was started. An increase of the intracellular PHA concentration from 1.08 to $13.64 \mathrm{~g} / \mathrm{L}$ was observed (Fig. 1c), which is attributed to inhibition of the cell growth and accumulation of the waxy carbon source and the remaining glucose from previous stages (Khanna and Srivastava 2007). The Hw concentration decreased $3.35 \mathrm{~g} / \mathrm{L}$ in the culture medium during the last $21 \mathrm{~h}$ of culture, with a consumption rate of $0.45 \mathrm{~g} / \mathrm{L} / \mathrm{h}$ (Fig. 2c).

Shang et al. (2004) registered the same consumption rate for $R$. eutropha NCIMB 11599 when feeding it with $<1.20 \mathrm{~g} / \mathrm{L}$ of valeric acid and glucose to produce $\mathrm{P}(3 \mathrm{HB}-\mathrm{co}-3 \mathrm{HV})$. The $\mathrm{Y}_{\mathrm{p} / \mathrm{s}}$ of $\mathrm{Hw}$ at the end of fermentation was $0.33 \mathrm{~g}_{\mathrm{p}} \mathrm{g}_{\mathrm{s}}$. Barbosa et al. (2005) reported a $Y_{x / s}$ of $0.1785 g_{x} / g_{s}$ for the production of PHB using glucose. The $\mathrm{Y}_{\mathrm{x} / \mathrm{s}}$ obtained in this work was higher $\left(0.225 \mathrm{~g}_{\mathrm{x}} / \mathrm{g}_{\mathrm{s}}\right)$. This indicates that $\mathrm{Hw}$ is a co-substrate (together with the remaining glucose in the previous stages) that accumulates PHA quickly under stress conditions (Fig. 1c).

Loo and Sudesh (2007) suggested that concentrations of $\mathrm{NH}_{4} \mathrm{Cl}$ lower than 0.5 and $5 \mathrm{~g} / \mathrm{L}$ of palm 
kernel oil promote the production of $87 \% \mathrm{w} / \mathrm{w}$ of PHA. During the PHA biosynthesis, it was observed that intracellular production of the polymer is favored as the concentration of $\mathrm{Hw}$ decreases in the reactor (Fig. 2c). In our work, the amount of synthesized sclmcl-PHA obtained after $45 \mathrm{~h}$ during the third stage of the fed-batch culture, corresponds to $65.3 \% \mathrm{w} / \mathrm{w}$ of the total biomass generated $(13.64 \mathrm{~g} / \mathrm{L})$.

In this regard, hydrolyzed beeswax ans its wastes are an attractive carbon source for the mass production of sustainable biopolymers. At the end of experiments, $95 \% \mathrm{w} / \mathrm{w}$ of Triton X-100 was recovered. The remaining $5 \% \mathrm{w} / \mathrm{w}$ should have been left in cell package (Budde et al. 2011).

\section{Nuclear magnetic resonance (NMR)}

The spectra of ${ }^{1} \mathrm{H}$ NMR of scl-mcl-PHA isolated from $C$. necator when grown on Hw as carbon source (third stage fed-batch culture) are shown in figure 3a. The corresponding signal to methine of the monomeric fraction of $3 \mathrm{HB}$ is observed as a sextet $5.24 \mathrm{ppm}$, which is a stereogenic center bonded to oxygen, methyl and methylene of PHA (Nurbas and Kutsal 2004, Impallomeni et al. 2011, Liu et al. 2011). This shift to low field is exerted by the deprotection effect caused by the electronegativity of the oxygen atom.

The methine groups of mcl-PHA monomers overlap with the signal of the methine of $3 \mathrm{HB}$. However, it should be seen as a quintuple signal, as a result of links with both methylene groups of the main chain and the aliphatic chain. The characteristic signals of $3 \mathrm{HB}$ and mcl-PHA monomers methylene groups are observed as an ABX system, because methylene protons are diastereotopic, and these are attached to the methine group from the main chain. The center of the signal for both monomers is observed at 2.50 ppm, as reported by several studies on PHA (Nurbas et al. 2004, Impallomeni et al. 2011, Liu et al. 2011, López-Cuéllar et al. 2011).

An additional signal was observed in the aliphatic region of the spectra with a displacement of $0.88 \mathrm{ppm}$, which is characteristic for terminal methyl groups of mcl-PHA monomers (Impallomeni et al. 2011, Liu et al. 2011, López-Cuéllar et al. 2011). The signal of $3 \mathrm{HB}$ methyl group observed at $1.32 \mathrm{ppm}$. However, it appears as a triplet due to signal overlaping with the signals corresponding to the methylene group of mcl-PHA monomers (Impallomeni et al. 2011, Liu et al. 2011).

The signal is a chemical shift of $1.56 \mathrm{ppm}$ corresponding to the methylene of the aliphatic chain attached to the stereogenic center of mcl-PHA mono- mers (Liu et al. 2011) originating from fatty acids contained as esters in the beeswax. The ${ }^{13} \mathrm{C}$ NMR spectra of the obtained biopolymer is shown in figure $\mathbf{3 b}$. The signals corresponding to the carbon, the methine, the methine and the methylene were visualized in 169.0, 67.6 and $40.7 \mathrm{ppm}$, respectively, for the monomers. The chemical shift for the methyl group is observed at $19.8 \mathrm{ppm}$ for HB while mcl-PHA monomers are observed in 14.1. ppm.

The remaining signals of the methylene groups of the aliphatic chain suggest the presence of $3 \mathrm{HD}$ monomer, observed between 22 and $35 \mathrm{ppm}$ (López-Cuéllar et al. 2011). Liu et al. (2011) reported the chemical shift of C-5 to 3-hydroxydodecanoate (3HDD) in $32 \mathrm{ppm}$; in this study, it was observed at $29.7 \mathrm{ppm}$, confirming the presence of 3-hydroxydecanoate (3HD) together with other monomers of mcl-PHA that do not appear in the ${ }^{13} \mathrm{C}$ NMR spectra. By ${ }^{1} \mathrm{H}$ NMR spectra, performing the integration of signals of the methyl, methylene and methine groups it was determined that the mclPHA monomers were in a proportion of $4.6 \mathrm{~mol} \%$ over the $3 \mathrm{HB}$. The monomer composition of the esters of fatty acids obtained in the mcl-PHA are consistent with those reported for biodegradable plastics.

\section{Thermal characterization}

DSC for the obtained scl-mcl-PHA (Fig. 4b) showed an endothermic transition at $79.8^{\circ} \mathrm{C}$ with a $\mathrm{DHm}$ of $45.6 \mathrm{~J} / \mathrm{g}$. This $\delta \mathrm{Hm}$ is similar to that reported by López-Cuéllar et al. (2011) $(\delta \mathrm{Hm} 41.44 \mathrm{~J} / \mathrm{g})$ for a mcl-PHA with 3HV, 3HO, 3HDD and 3HB monomers. Liu et al. (2011) obtained a PHA with 3HD monomers using a strain of Pseudomonas putida KTQQ20 inhibiting the $\beta$-oxidation, which consumed decanoic, dodecanoic, and tetradecanoic acids.

The obtained polymer had 3HD and 3HDD monomers, $\mathrm{P}(16 \mathrm{~mol} \% 3 \mathrm{HD}-\mathrm{co}-84 \mathrm{~mol} \% 3 \mathrm{HDD})$ with a $\mathrm{T}_{\mathrm{m}}$ of $78^{\circ} \mathrm{C}$, attributed to the presence of 3HDD and 3HD monomers, $\mathrm{P}(16 \mathrm{~mol} \%$ 3HD-co-3HDD $84 \mathrm{~mol} \%)$ and a $\delta \mathrm{Hm}$ of $41 \mathrm{~J} / \mathrm{g}$, similar to that obtained in this study and reported for mcl-PHA (López-Cuéllar et al. 2011).

The $\mathrm{T}_{\mathrm{m}}$ in this mcl-PHA was $79.82{ }^{\circ} \mathrm{C}$, lower than the one reported by López-Cuéllar et al. (2011); $133{ }^{\circ} \mathrm{C}$. This result suggests that the scl-mcl-PHA obtained may contain a percentage of medium-chain monomers. Also, the monomer length presented fractions of 3-hydroxydodecanoate (3HDD), which reduce the recrystallization of polymeric material and consequently its melting point (Khanna and Srivastava 2007), with respect to PHB (Fig. 4a). 
a)
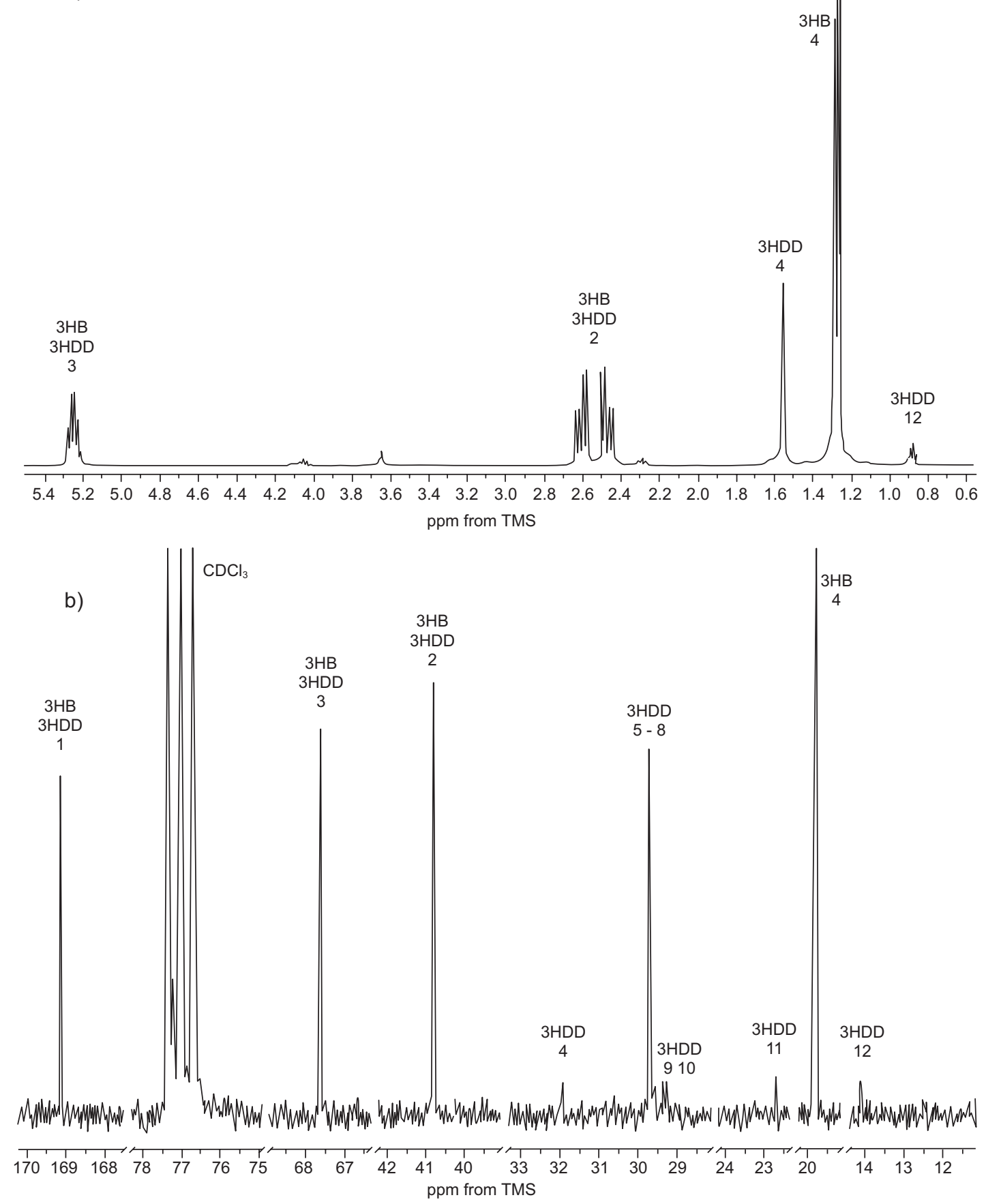

Fig. 3. Nuclear magnetic resonance (NMR) spectra at $300 \mathrm{MHz}$ of short- or medium-chain-length polyhydroxyalkanoates (scl-mcl-PHA) obtained by C. necator: 3-hydroxybutyrate (3HB), 3-hydroxydecanoate (3HD) in deuterated chloroform $\left(\mathrm{CDCl}_{3}\right)$. Chemical shifts are in parts per million downfield from tetramethylsilane (TMS). (a) ${ }^{1} \mathrm{H}$ spectra, (b) ${ }^{13} \mathrm{C}$ spectra

Volova et al. (2014) reported this thermal phenomenon, realizing that as the molar fraction of $3 \mathrm{HB}$, $3 \mathrm{HV}$ and $3 \mathrm{HHx}$ was modified $(92.6,1.3,6.1$ to 71.4 ,
$26.1,2.5 \mathrm{~mol} \%$, respectively) in the terpolymer $\mathrm{P}(3 \mathrm{HB} / 3 \mathrm{HV} / 3 \mathrm{HHx})$, the degree of crystallinity of the polymer decreased (from 62 to $53 \mathrm{~mol} \%$ ), but the $\mathrm{T}_{\mathrm{m}}$ 


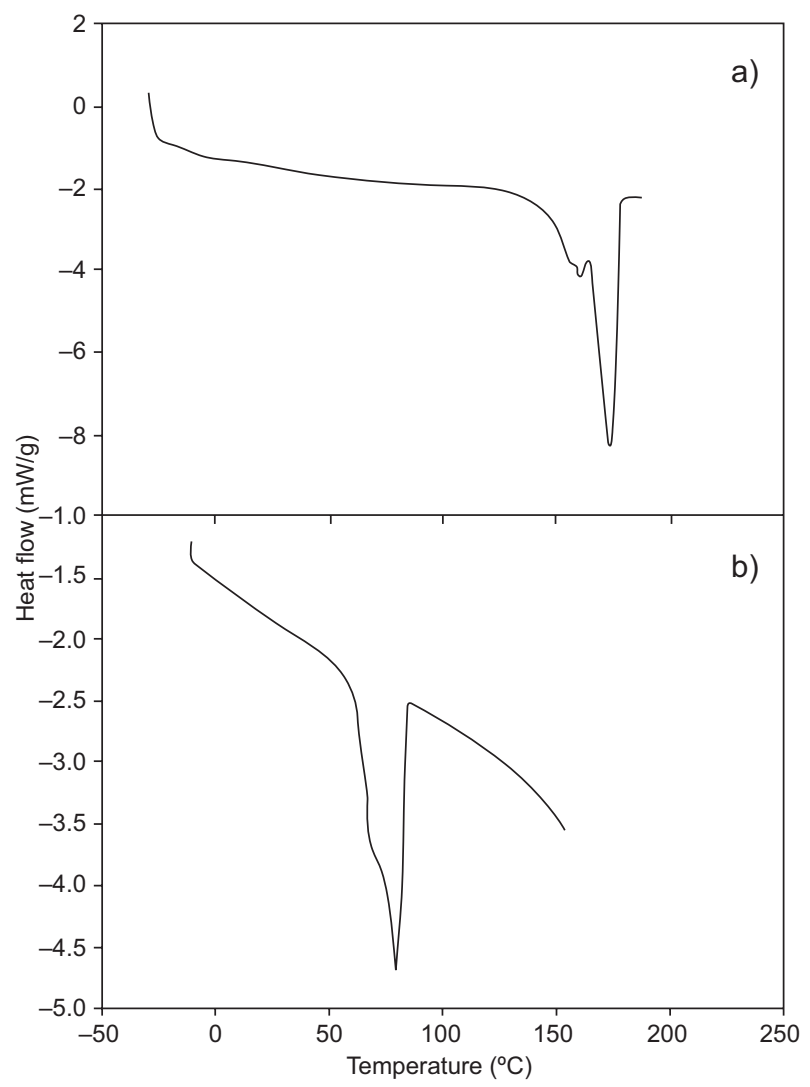

Fig. 4. Thermogram of short- or medium-chain-length polyhydroxyalkanoates (scl-mcl-PHA) synthesized by Cupriavidus necator using glucose and hydrolyzates (Hw) as carbon source. (a) Poly-3-hydroxybutyrate (P3HB), (b) poly-3-hydroxybutyrate-3-hydroxydecanoate (P3HBco-3HDD)

increased (from 173 to $175^{\circ} \mathrm{C}$ respectively). When mcl-PHA was obtained by gradually heating $\left(-80^{\circ} \mathrm{C}\right.$ to $220^{\circ} \mathrm{C}$ ) $\mathrm{T}$ g was observed at $-52^{\circ} \mathrm{C}$. Impallomelli et al. (2011) reported similar values for mcl-PHA $\left(\mathrm{T}_{\mathrm{g}}-52\right.$ to $-43^{\circ} \mathrm{C}$ ), with similar characteristics to elastomeric materials, due to the crystallization of comonomers of medium chain length into the PHA.

During the cooling of scl-mcl-PHA, a sequence reverse transition with hysteresis (exothermic peaks) was observed at $112.33^{\circ} \mathrm{C}$ with a $\delta \mathrm{Hc}$ of $36.13 \mathrm{~J} / \mathrm{g}$ (data not shown). We suggest that this decline of $\delta \mathrm{Hc}$ in the cooling process can be described as recrystallization by the possible presence of PHB crystals dispersed among medium chain length monomers (López-Cuéllar et al. 2011). Impallomeni et al. (2011) hypothesize that such biodegradable polymeric materials crystallize with the participation of both the main chain and the side chains in a layered order, similarly to what happens with polymers carrying long side chains.

\section{CONCLUSION}

C. necator was able to synthesize scl-mcl-PHA using $\mathrm{Hw}$ as carbon source under $\mathrm{N}$ limiting conditions in a three stages fed batch fermentation system. The increase in the consumption rate of $\mathrm{Hw}$ showed that the carbon source is assimilated by $C$. necator, favoring the production of scl-mcl-PHA inclusions. Adding hydrolyzed beeswax in the presence of Triton X-100 did not affect the growth of $C$. necator, which makes it a promising strategy that facilitates an economically feasible process of PHA production.

The ${ }^{1} \mathrm{H}$ and ${ }^{13} \mathrm{C} \mathrm{RMN}$ analysis determined that the obtained polymer has a relationship of $4.6 \mathrm{~mol} \%$ of mcl-PHA monomers due to the incorporation of $\mathrm{Hw}$ fractions during the biosynthesis. The thermal properties of these materials are affected by the addition of medium chain length monomers, which reduce their melting point. The scl-mcl-PHA synthesized in this study may be used in agriculture, radio electronics, medicine, and pharmacology as an environmentally friendly material to replace petrochemical plastics.

\section{ACKNOWLEDGMENTS}

This work was supported by fellowship 373182 form the Consejo Nacional de Ciencia y Tecnología.

\section{REFERENCES}

Alibaba (2017). Product catalog. [online] http://www.alibaba.com/showroom/caprylic-acid-price.html 08/11/17.

Barbosa M., Hernández E.A, Malagón R.D. and Moreno S.N. (2005). Producción de poli-b-hidroxibutirato (PHB) por Ralstonia eutropha ATCC 17697. Univ. Sci. 10 (1), 45-54.

Bradbear N. (2004). Beekeeping and sustainable livelihoods. 2da ed. FAO Press, Rome, Italy, 62 pp.

Budde C.F., Riedel S.L., Hübner F., Risch S., Popović M.K., Rha C.K. and Sinskey A.J. (2011). Growth and polyhydroxybutyrate production by Ralstonia eutropha in emulsified plant oil medium. Appl. Microbiol. Biotechnol. 89 (5), 1611-1619. DOI: $10.1007 / \mathrm{s} 00253-011-3102-0$

Chakraborty P., Muthukumarappan K. and Gibbons W.R. (2012). PHA productivity and yield of Ralstonia eutropha when intermittently or continuously fed a mixture of short chain fatty acids. J. Biomed. Biotechnol. 2012 (1-13). DOI: 10.1155/2012/506153

Cruz M.V., Freitas F., Paiva A., Mano F., Dionísio M., Ramos A.M. and Reis M.A. (2015). Valorization of 
fatty acids-containing wastes and by products into short and medium chain length polyhydroxyalkanoates. $\mathrm{N}$. Biotechnol. 33 (1), 206-215.

DOI: 10.1016/j.nbt.2015.05.005

Impallomeni G., Ballistreri A., Carnemolla G.M., Guglielmino S., Nicolò M.S. and Cambria M.G. (2011). Synthesis and characterization of poly(3-hydroxyalkanoates) from Brassica carinata oil with high content of erucic acid and from very long chain fatty acids. Int. J. Biol. Macromol. 48 (1), 137-145.

DOI: 10.1016/j.ijbiomac.2010.10.013

Inomata M., Vilas T., Santos L. and Druzianba J. (2014). The influence of crude glycerin and nitrogen concentrations on the production of PHA by Cupriavidus necator using a response surface methodology and its characterizations. Ind. Crop. Prod. 52, 338-346.

DOI: 10.1016/j.indcrop.2013.11.008

Jiang X. (2010). Process development for the production and separation of medium-chain-length Poly(3hydroxyalkanoates) by Pseudomonas putida KT2440. $\mathrm{PhD}$. Thesis. Queen's University, Kingston, Ontario, Canada, 155 pp.

Khanna S. and Srivastava A.K. (2007). Production of poly(3-hydroxybutyric-co-3-hydroxyvaleric acid) having a high hydroxyvalerate content with valeric acid feeding. J. Ind. Microbiol. Biotechnol. 34 (6), 457-461. DOI: 10.1007/s10295-007-0207-7

Liu Q., Luo G., Zhou X.R. and Chen G.Q. (2011). Biosynthesis of poly(3-hydroxydecanoate) and 3-hydroxydodecanoate dominating polyhydroxyalkanoates by b-oxidation pathway inhibited Pseudomonas putida. Metab. Eng. 13 (1), 11-17.

DOI: 10.1016/j.ymben.2010.10.004

Loo C.Y. and Sudesh K. (2007). Polyhydroxyalkanoates: Bio-based microbial plastics and their properties. Malaysian Polymer Journal 2 (2), 31-57.

López-Cuéllar M.R., Alba-Flores J., Gracida Rodríguez J.N. and Pérez-Guevara F. (2011). Production of polyhydroxyalkanoates (PHAs) with canola oil as carbon source. Int. J. Biol. Macromol. 48 (1), 74-80.

DOI: 10.1016/j.ijbiomac.2010.09.016
Maia M. and Nunes F.M. (2013). Authentication of beeswax (Apis mellifera) by high-temperature gas chromatography and chemometric analysis. Food Chem. 136 (2), 961-968.

DOI: $10.1016 /$ j.foodchem.2012.09.003

Nurbas M. and Kutsal T. (2004). Production of PHB and P(HB-co-HV) biopolymers by using Alcaligenes Eutrophus. Iran Polym. J. 13 (1), 45-51.

Rathinasabapathy A., Ramsay B.A., Ramsay J.A. and Pérez-Guevara F. (2013). A feeding strategy for incorporation of canola derived medium-chain-length monomers into the PHA produced by wild-type $C u$ priavidus necator. World J. Microbiol. Biotechnol. 30 (4), 1409-1416.

DOI: $10.1007 / \mathrm{s} 11274-013-1563-2$

Shang L., Yim S.C., Park H.G. and Chang H.N. (2004). Sequential feeding of glucose and valerate in a fedbatch culture of Ralstonia eutropha for production of poly(hydroxybutyrate-co-hydroxyvalerate) with high 3-hydroxyvalerate fraction. Biotechnol. Prog. 20 (1), 140-144.

DOI: $10.1021 / \mathrm{bp} 0342320$

Slater S., Gallaher T. and Dennis D. (1992). Production of poly-(3-hydroxybutyrate-co-3-hydroxyvalerate) in a recombinant Escherichia coli strain. Appl. Environ. Microbiol. 58 (4), 1089-1094.

Volova T., Kiselev E., Vinogradova O., Nikolaeva E., Chistyakov A., Sukovatiy A. and Shishatskaya E. (2014). A glucose-utilizing strain, Cupriavidus euthrophus B-10646: growth kinetics, characterization and synthesis of multicomponent PHAs. Plos One 9 (2), e87551.

DOI: 10.1371 /journal.pone. 0087551

Zhang D. and Xiao H. (2013). Dual-functional beeswaxes on enhancing antimicrobial activity and water vapor barrier property of paper. ACS. Appl. Mater. Inter. 5 (8), 3464-3468.

DOI: $10.1021 / \mathrm{am} 400585 \mathrm{~m}$ 